\title{
Luta nas ruas contra o espetáculo?'
}

Anselm Jappe ${ }^{2}$

I Tradução de Juliana Zanetti de Paiva, Mestranda do Instituto de Estudos da Linguagem - IEL Unicamp; bolsista da FAPESP.

2 Anselm Jappe (1962-) nasceu em Bonn, Alemanha, estudou filosofia em Roma e Paris, onde se doutora pela École des Hautes Études en Sciences Sociales. É professor na Accademia di Belle Arti di Frosinone, Itália, e dá cursos na EHESS. Estudou a obra de Guy Debord e dos situacionistas, as vanguardas artísticas, o marxismo, a Escola de Frankfurt $e$ as transformações da subjetividade contemporânea. Dedica-se à elaboração da "crítica do valor" nas revistas alemãs Krisis e Exit!, fundadas por Robert Kurz. Publicou em português: Guy Debord (Vozes, 1999; Antígona, 2008), As aventuras da mercadoria (Antígona, 2006), Conferências de Lisboa (Antígona, 2013), Crédito a morte (Hedra, 2013), O "fim da arte" segundo Theodor W. Adorno e Guy Debord (Centelha viva, 20 10). 
As teorias sociais nascem para explicar os acontecimentos da sua época, mais ou menos pertinentes. Com os anos que passam, e a sociedade que muda, o valor heurístico delas tende a diminuir. O tribunal da história retém, portanto, somente aquelas leituras da realidade que demonstram poder ser aplicadas a situações diferentes daquelas em que nasceram, porque elas capturaram as tendências gerais de uma época mais ampla. Essas teorias não são "proféticas" (categoria vazia), mas souberam compreender a essência de um longo período histórico. Aqueles que hoje se reivindicam ainda da época de Tocqueville, ou Marx, ou Weber, ou Pareto, afirmam que estes apreenderam, um ou quase dois séculos passados, alguns elementos da sociedade moderna que estão presentes ainda hoje, embora de modo diferente. Em contrapartida, teorias também mais recentes que, para dar um exemplo, viam na aliança entre operários de fábrica e cidadãos um elemento capaz de transformar a sociedade capitalista nos parecem já irremediavelmente datadas.

As teorias elaboradas nos anos cinquenta e sessenta do século passado pelos situacionistas, e por Guy Debord particularmente, fazem parte desta análise de efeito prolongado? São capazes de nos ajudar a compreender os fenômenos que estes autores ainda não podiam conhecer? A categoria crítica do "espetáculo", uma vez esclarecido que descreve um fenômeno muito mais amplo do que o poder excessivo da televisão, aplica-se também à dimensão política e social do mundo globalizado, quarenta e cinco anos depois da publicação do livro de Debord?

É ainda muito cedo para exprimir um parecer sobre as contestações que desde maio de 2013 abalaram primeiro a Turquia e depois o Brasil. Esses movimentos de protesto, de um teor bem diferente daquele expresso pelos Indignados, pelo Occupy Wall Street e pelas Primaveras árabes, como se explicará adiante, surpreenderam todos os observadores e produziram muitas análises visivelmente confusas e insuficientes. Por outro lado, alguns dos conceitos situacionistas possam talvez ajudar a compreender vários traços relevantes e inovadores desses movimentos que parecem escapar à sociologia e ciência política tradicionais, tanto de esquerda quanto de direita.

Os situacionistas atribuíram a si próprios o mérito de ter contribuído fortemente para preparar o clima do qual nasceu o Maio de 68 na França e de ter expressado 
ano 2 número 3

Fora de Quadro

o seu conteúdo profundo, independentemente da questão de uma "influência" direta. O 68 francês pegou de surpresa quase todos os observadores, e não foi a consequência de uma crise econômica maior. Os protestos na Turquia e no Brasil chegam do mesmo modo "inexplicável”, isto é, após vários anos de forte desenvolvimento econômico, e quem protesta são as mesmas novas classes médias, jovens, que aproveitaram fortemente esse crescimento. Parece um paradoxo. Alguns economistas se apressam agora em explicar o descontentamento com uma diminuição do crescimento e o retorno da inflação. Ou, de forma mais geral, com as expectativas que esse desenvolvimento teria criado sem poder satisfazê-las, sobretudo no âmbito dos serviços públicos. Isso significa, porém, assumir que o desenvolvimento capitalista, a sua forma de riqueza e o consumo que permite sejam por si só desejáveis e que a insatisfação social nasça somente quando faltam ou já não mais existem essa riqueza e esse consumo. Ora, os situacionistas estavam entre os primeiros a proclamar que a vida no capitalismo é sempre alienante, mesmo quando a pobreza em massa desaparece. "A questão não é constatar que as pessoas vivem mais ou menos pobremente, mas sempre de modo que lhes escapa", disse Debord em um filme seu de 1961, e no livro $A$ sociedade do espetáculo afirmou, em 1967, que "agora é a abundância capitalista que fracassou" (§115). Esta pode garantir a "sobrevivência", mas não a "vida". Essa análise, que se encontrava em contraposição com o marxismo tradicional, mas em paralelo com pensamentos como aquele de Herbert Marcuse, revelouse clarividente quanto à explosão de 68 e a sua continuidade: a existência no capitalismo evidencia-se sempre insuportável, mesmo quando a marmita está cheia. E se as pessoas que se manifestam hoje com tanta constância nas ruas das cidades turcas e brasileiras exprimem raramente ideias claramente anticapitalistas, constata-se, ao mesmo tempo, que os pretextos iniciais (corte de árvores em um parque em Istambul, preço das passagens dos transportes públicos no Brasil) foram rapidamente superados. O que se percebe é uma insatisfação geral com a vida que se é obrigado a levar, mesmo que nem sempre se saiba denominá-la.

O próprio fato de muitos estarem nas ruas, de bloquearem o curso normal da infelicidade, a própria ruptura com o quotidiano, o sentimento de força e de vingança que derivam da ocupação do espaço público e de estar junto implicam 
ano 2 número 3

Fora de Quadro aquela "crítica da vida cotidiana" em ação que esteve sempre no centro da agitação situacionista. Não se manifesta somente para conseguir a aprovação de uma reivindicação concreta e em seguida retornar para casa ou para o trabalho, mas também para fugir da passividade organizada e do tédio de uma vida conduzida por outros. "We want to riot, not to work" (Queremos nos amotinar, não trabalhar), já diziam os revoltosos de Brixton em 1981, escandalizando os conformistas tanto da esquerda quanto da direita. Enquanto a esquerda tradicional permanece desconcertada diante do caráter "apolítico" do movimento no Brasil, algumas das suas características parecem a confirmação do que os situacionistas preconizavam: um movimento sem chefes nem programas, que se situa fora de partidos e sindicatos, nem deseja formar outros, porque recusa a "política" no seu sentido tradicional tout court e julga que a suposta esquerda não se distingue da direita. (Claro, por outros aspectos, isso está bem distante do que queriam os situacionistas, que evocavam revoltas proletárias, conselhos operários e ocupações de fábrica).

Os situacionistas foram também os pioneiros quando indicavam um novo terreno central das lutas sociais no urbanismo e na oposição à reestruturação autoritária e mercantil do espaço urbano e ao desaparecimento dos lugares públicos e das trocas diretas entre indivíduos nos espaços que esses lugares permitem. Imediatamente constatou-se a importância desses temas na Turquia, onde o pomo da discórdia foi a transformação de um parque em um shopping, e, em geral, a devastação de Istambul por conta de megaprojetos arquitetônicos, e, no Brasil, onde a questão dos transportes foi o detonador.

Mas o aspecto mais notável parece residir no que se pode chamar a contestação do "espetáculo". Por "espetáculo", Debord e os situacionistas não compreendiam somente as mídias, mas uma organização social onde os indivíduos consomem sob a forma de imagens e de ideologias tudo aquilo que a sociedade capitalista os impede de viver realmente. Aqui se inserem tanto a religião como o consumismo, tanto o star system como a política dos partidos e dos dirigentes. Aquilo que não existe na vida, contempla-se em cima de um palco ou em uma tela (termo a ser considerado também em um sentido mais amplo). O espetáculo é, portanto, uma continuação da religião na época das mercadorias, das imagens reproduzidas maciçamente e do consumo compensatório. Ora, as revoltas na Turquia e no Brasil contestam um aspecto central da alienação espetacular nos respectivos países. 
ano 2 número 3

Fora de Quadro
Na Turquia, (e isso constitui uma grande diferença com as Primaveras árabes) combatia-se o retorno à "ordem moral" imposta por um governo islamista que quer banir o álcool e instiga as mulheres a terem "pelo menos três filhos". Ainda mais espetacular é colocar em discussão o espetáculo no Brasil: como todos sabem, o futebol aqui desempenha, há muitos anos, um papel absolutamente central na alienação cotidiana e funciona como "ópio do povo". O governo podia esperar também que as despesas mais desvairadas e inúteis e a destruição dos bairros populares vizinhos às instalações esportivas fossem aceitas, visto que se tratava do futebol. A recusa generalizada, manifestada de repente, em sacrificar os interesses imediatos da vida em detrimento do espetáculo esportivo constitui, nesse momento, a verdadeira surpresa! Dezenas ou centenas de milhares de pessoas marcham a cada partida da "Copa das Confederações" para conseguir chegar ao estádio, confrontando-se frequentemente com a polícia, enquanto alguns torcedores contestam no interior do estádio. O slogan "mais pão, menos circo, Copa pra quem?" encontrou um amplo consenso. De acordo com as pesquisas, um terço dos brasileiros é contrário à realização da Copa do Mundo no Brasil! Muitos observadores se dizem perplexos diante de um movimento que, aparentemente, não sabe o que fazer com a sua força e que no seu interior convivem indivíduos os mais diversos, e onde cada um chega com a sua reivindicação personalizada em um cartaz. Mas se pode já dizer de antemão que a ideologia esportiva, pedra fundamental no processo de passividade da população brasileira, perdeu quase toda a sua função. E isso poderia ser mais grave para o sistema do que a perda da confiança nos partidos e nos políticos, ou seja, no espetáculo político, no qual ninguém mais crê faz muito tempo e que continua o mesmo. A vida real, cotidiana, descobre a sua miséria e não aceita mais esquecê-la na contemplação de uma perfeição ilusória.

Evidentemente, muitos outros aspectos dessas contestações de novo tipo não são imediatamente perceptíveis com as categorias anunciadas na época dos situacionistas. Mas considerando o temor da maior parte dos comentaristas profissionais, e a evidente obsolescência de muitas categorias interpretativas, a utilidade parcial das intuições situacionistas de quase meio século não pode senão confirmar a sua pertinência. 